\title{
Coffee Modulates the Function of Brain-Derived Neurotrophic Factor (BDNF) in Human Neuroblastoma SH-SY5Y Cells
}

\author{
Shota Kakio, Yosuke Nakazawa, Megumi Funakoshi-Tago, Hiroomi Tamura* \\ Graduate School of Pharmaceutical Sciences, Keio University, Tokyo, Japan \\ Email: "tamura-hr@pha.keio.ac.jp
}

Received 17 November 2015; accepted 21 December 2015; published 24 December 2015

Copyright ( 2015 by authors and Scientific Research Publishing Inc.

This work is licensed under the Creative Commons Attribution International License (CC BY). http://creativecommons.org/licenses/by/4.0/

(c) (i) Open Access

\begin{abstract}
Recent epidemiological studies showed that daily coffee consumption is associated with a lower risk for several neurological disorders such as Alzheimer's disease and Parkinson's disease; however, the molecular mechanisms responsible for the protective effect of coffee against neurological disorders have not been elucidated. As brain-derived neurotrophic factor (BDNF) promotes neuronal survival and protects against neuronal damage, we investigated the effects of coffee on BDNF signaling using human neuroblastoma SH-SY5Y cells. We found that brewed coffee exerted an inhibitory effect on the autophosphorylation of tropomyosin receptor kinase B (TrkB), a BDNF receptor. Additionally, coffee reduced the phosphorylation of Akt in BDNF-treated SH-SY5Y cells. Treatment with coffee did not affect the TrkB receptor on the cell surface. The major constituents of coffee, such as caffeine, caffeic acid, chlorogenic acid, and trigonelline had no effect on TrkB phosphorylation induced by BDNF. In addition, coffee reduced the BDNF-induced increase in BDNF gene expression and the neurite outgrowth promoted by BDNF. Our data suggest that the protective effect of coffee reported in epidemiological studies against neurological disorders may not be associated with BDNF signaling through TrkB.
\end{abstract}

\section{Keywords}

BDNF, Coffee, Neuroprotection, TrkB

\section{Introduction}

Brain-derived neurotrophic factor (BDNF), a neurotrophin, is a member of the nerve growth factor (NGF)-re-

\footnotetext{
${ }^{*}$ Corresponding author.
}

How to cite this paper: Kakio, S., Nakazawa, Y., Funakoshi-Tago, M. and Tamura, H. (2015) Coffee Modulates the Function of Brain-Derived Neurotrophic Factor (BDNF) in Human Neuroblastoma SH-SY5Y Cells. Neuroscience \& Medicine, 6, 165-174. http://dx.doi.org/10.4236/nm.2015.64025 
lated family [1]. BDNF promotes neuronal survival and protects against neuronal damage [2]. It also regulates the synaptic plasticity through the activation of its receptor, the tropomyosin receptor kinase B (TrkB), in the hippocampus, cortex, and basal forebrain [3]. Additionally, BDNF signaling regulates learning and memory, including recognition memory [4] [5]. Upon the binding of BDNF homodimers, TrkB receptors dimerize, autophosphorylate each other, and activate various signaling pathways. Dysfunction of BDNF is associated with several neurological disorders, such as depression [6] [7], dementia [8], Alzheimer's disease (AD) [9], and Parkinson's disease (PD) [10].

Coffee is one of the world's most commonly consumed beverages. Epidemiological studies showed that coffee consumption might be associated with a lower risk for several neurological disorders such as AD and PD [11] [12]. A recent study proposed that caffeine might maintain the physiological levels of BDNF, as it had a positive effect on cognition [13]-[15]. Another recent study showed that coffee fruit extract had a modulatory effect on the plasma levels of BDNF in healthy human subjects [16]. However, it is still unknown which molecular mechanism is responsible for the protective effect of coffee against neurological disorders associated with BDNF signaling. To investigate the possible role of BDNF in the protective effect of coffee against neurological disorders, we analyzed the effects of coffee on TrkB-mediated BDNF signaling in human neuroblastoma SH-SY5Y cells.

\section{Materials and Methods}

\subsection{Materials}

SH-SY5Y cells were purchased from DS Pharma Biomedical Co. Ltd. (Osaka, Japan). All-trans retinoic acid (ATRA) was purchased from Wako Pure Chemical Industries (Osaka, Japan). BDNF was obtained from PeproTech (Rocky Hill, NJ). Caffeic acid, caffeine, chlorogenic acid, trigonelline, and reagents for the MTT assay were purchased from Sigma (St. Louis, MO). Inhibitor cocktails for phosphatases and proteases were purchased from NacalaiTescque, Kyoto, Japan).

\subsection{Preparation of Coffee Extract}

Roasted coffee powder (Columbia arabica) was obtained from Starbucks Coffee Japan (Tokyo, Japan). Coffee extracts were prepared by a commonly utilized method (drip style), where $8 \mathrm{~g}$ of ground coffee was poured with $140 \mathrm{~mL}$ hot water $\left(95^{\circ} \mathrm{C}\right)$, filtered through a paper filter (Mellita, Minden, Germany). The brewed coffee was divided into small aliquots and stored at $-80^{\circ} \mathrm{C}$ until used. The undiluted coffee extract, with a dry weight of 8.4 $\mathrm{mg} / \mathrm{ml}$, was assigned a concentration value of $100 \%(\mathrm{v} / \mathrm{v})$.

\subsection{Cell Culture}

SH-SY5Y cells were grown in Ham's F12 (+glutamine)/DMEM(high glucose) medium (1:1 mixture) supplemented with $1 \%$ non-essential amino acid solution, $15 \%$ fetal bovine serum, and a mixture of $100 \mathrm{U} / \mathrm{mL}$ penicillin and $100 \mu \mathrm{g} / \mathrm{mL}$ streptomycin (NacalaiTesque, Kyoto, Japan) at $37^{\circ} \mathrm{C}$ in a humidified atmosphere of $5 \% \mathrm{CO}_{2}$. For differentiation, the cells were exposed to $10 \mu \mathrm{M}$ ATRA for 6 days. The medium was changed every 48 hours.

\subsection{Treatment with Coffee and Its Components}

The cultured cells were exposed to coffee at 0 and $2.0 \%(\mathrm{v} / \mathrm{v})$, and to major coffee constituents at $100 \mu \mathrm{M}$. After 2 hours of exposure, $20 \mathrm{ng} / \mathrm{mL}$ BDNF was added. To analyze concentration dependency, cells were exposed to coffee at $0,0.25,0.5,1.0$, and $2.0 \%(\mathrm{v} / \mathrm{v})$ for 2 hours followed by a treatment with $20 \mathrm{ng} / \mathrm{mL}$ BDNF for $15 \mathrm{mi}-$ nutes.

\subsection{Analysis of TrkB and Akt Phosphorylation}

Differentiated cells were treated with $20 \mathrm{ng} / \mathrm{mL}$ BDNF for 15 minutes. Cells were lysed in Nonidet P-40 lysis buffer (50 mMTris-HCl (pH 8.0), 120 mMNaCl, 1 mM EDTA (pH 8.0), 0.5\% Nonidet P-40, phosphatase inhibitor cocktail and protease inhibitor cocktail). Protein concentration was measured using the Bradford reagents (Bio-Rad). Western blot analysis was performed for TrkB, TrkB phosphorylated at Tyr (516) [pTrkB(Y516)], 
Akt, phosphorylated Akt (pAkt), and $\beta$-actin. Protein samples (50 $\mu$ g for TrkB; $5 \mu$ g for Akt and $\beta$-actin) were resolved using sodium dodecyl sulfate polyacrylamide gel electrophoresis (SDS-PAGE), and then were electrotransferredto a polyvinylidene difluoride membrane (Millipore; Billerica, MA). The membrane was blocked for 1 hour at room temperature in $5 \%$ skim milk or $1 \%$ bovine serum albumin in TBS $(20$ mMTris- $\mathrm{HCl}(\mathrm{pH} 7.6)$, $137 \mathrm{mM} \mathrm{NaCl}$ ). The membrane was incubated overnight at $4{ }^{\circ} \mathrm{C}$ in the primary antibody. The primary antibodies were the following: rabbit monoclonal anti-TrkB (1:1000), rabbit monoclonal anti-pTrkB (Y516) (1:1000), rabbit monoclonal anti-pAkt(S473) (1:1000) (all obtained from Cell Signaling Technology, Danvers, MA), mouse monoclonal anti-Akt1 (1:1000), and goat polyclonal anti- $\beta$-actin (1:2000) (both from Santa Cruz Biotechnology Inc., Santa Cruz, CA). The next day, the membrane was incubated in anti-rabbit, anti-mouse, or anti-goat IgG secondary antibodies conjugated with horseradish peroxidase (GE Healthcare; Little Chalfont, U.K.). Immunoreaction was visualized with the ECL detection system (GE Healthcare) and quantified with Quantity One Software (Bio-Rad Laboratories, Hercules, CA).

\subsection{Analysis of TrkB Expression on the Cell Surface}

Differentiated cells were washed with phosphate buffered saline (PBS), and were removed from the culture dish with $0.25 \%$ trypsin and $1 \mathrm{mM}$ EDTA. Cells were then incubated with anti-TrkB antibody conjugated with phycoerythrin (PE) (Sino Biological Inc., Beijing, China) for 15 minutes on ice, rinsed twice with PBS, and the cell pellets were resuspended in $500 \mu \mathrm{L}$ PBS. The labeled samples were analyzed using the LSR II Flow Cytometer System (BD Biosciences, Seattle, WA).

\subsection{Analysis of Gene Expression}

Total RNA was isolated from the cells after 4 hours of BDNF treatment, and first-strand cDNA was synthesized from $1 \mu \mathrm{g}$ total RNA using 100 units of reverse transcriptase and random primers. Quantitative real-time PCR (qPCR) was performed using the ABI 7300 thermal cycler and SYBR Green PCR Core Reagent kit (Applied Biosystems Inc., Warrington, UK). The primers used for the detection of BDNF and TrkB were as follows: BDNF, 5'-GAA GGC TGC AGG GGC ATA GAC-3' (forward) and 5'-TAC ACA AGA AGT GTC TAT CCT TAT-3' (reverse) (135bp); TrkB, 5'-ACG ATG GTG CAA ACC CAA AT-3' (forward) and 5'-CCG GTT TTA TCA GTG ACG TCT GT-3' (reverse) (127 bp). Complementary DNAs were denatured at $94^{\circ} \mathrm{C}$ for $10 \mathrm{~min}$ and were amplified for 40 cycles (denaturation at $94^{\circ} \mathrm{C}$ for $30 \mathrm{~s}$ followed by annealing and extension at $60^{\circ} \mathrm{C}$ for 60 s). Amount of the target gene normalized to the reference gene (18S rRNA) was quantified using the cycle threshold (Ct) values.

\subsection{Determination of Neurite Length}

SH-SY5Y cells $(2.0 \times 105$ cells/well $)$ were seeded into 6-well plates coated with collagen type 1 , and the cells were cultured for 24 hours. The next day, the cells were exposed to ATRA for differentiation. On the fourth day, the cells were exposed to coffee at $0,0.25,0.5,1.0$, and $2.0 \%(\mathrm{v} / \mathrm{v})$ for 2 hours followed by a treatment with 50 $\mathrm{ng} / \mathrm{mL}$ BDNF. On the sixth day, the cultured cells were observed using a phase-contrast microscope, and four different locations were photographed in each well. Neurite length was measured with the ImageJ image analysis software (National Institutes of Health, Bethesda, MD).

\subsection{Statistics}

Student's t-test was used for statistical analysis, and $p<0.05$ was considered as significant.

\section{Results}

\subsection{Effects of Coffee on BDNF-Mediated TrkB Phosphorylation in SH-SY5Y Cells}

To examine whether coffee affects the BDNF/TrkB signaling pathway, we measured the effects of coffee on the autophosphorylation of TrkB elicited by BDNF binding in human neuroblastoma SH-SY5Y cells. Because TrkB expression is very low in undifferentiated neuronal cells, the SH-SY5Y cells were differentiated with $10 \mu \mathrm{M}$ ATRA for 6 days. TrkB expression was induced in the ATRA-treated SH-SY5Y cells as previously described (Figure 1) [17]. Differentiated cells were treated with $20 \mathrm{ng} / \mathrm{mL}$ BDNF for 15 minutes after exposure to coffee 


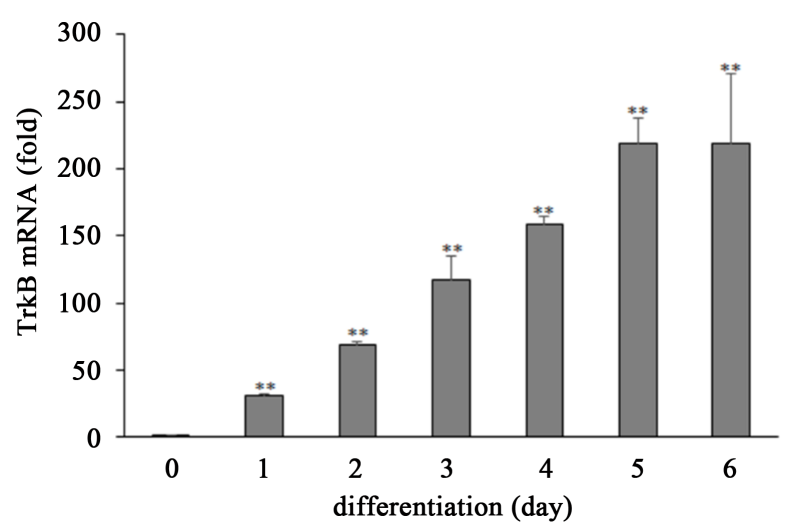

(A)

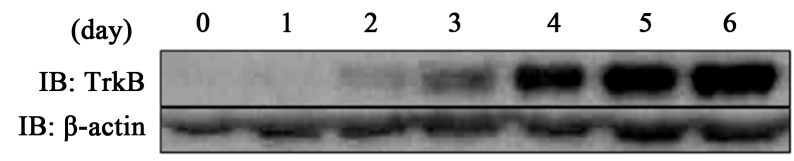

(B)

Figure 1. ATRA-mediated induction of TrkB expression in SH-SY5Y cells. (A) SH-SY5Y cells were treated with $10 \mu \mathrm{M}$ all-trans retinoic acid (ATRA) for 6 days. Cells were harvested on each day of the experiment, and tropomyosin receptor kinase B (TrkB) expression was measured with quantitative real-time PCR (A) and immunoblotting (B). ${ }^{* *} p<0.01(\mathrm{n}=3)$.

at $0 \%, 0.25 \%, 0.5 \%, 1 \%$, and $2 \%(\mathrm{v} / \mathrm{v})$ for 2 hours. No cytotoxicity was observed following coffee exposure at any concentrations up to $5 \%(\mathrm{v} / \mathrm{v})$ as judged by trypan blue staining (data not shown). Coffee reduced the phosphorylation of TrkB at tyrosine 516 (Y516), which is essential for Akt activation, in a concentration-dependent manner (Figure 2(A)).

Phosphorylated TrkB activates the Shc protein and thus activates of the phosphatidylinositol-3-kinase (PI3K)/Akt signaling cascade, which regulates cell survival and differentiation [1]. Therefore, we measured the effect of coffee on the activation of Akt in BDNF-treated SH-SY5Y cells. Coffee reduced the BDNF-triggered activation of Akt in SH-SY5Y cells as shown in Figure 2(B). Quantitative analysis of band intensities also indicated a significant reduction in the ratio of phosphorylated-Akt/Akt at $2.0 \%$ coffee $(0.27 \pm 0.14$ compared to the controls ( $=1.0$ at $0 \%$ coffee) $(n=3)$ ).

Brewed coffee contains hundreds of components, and major antioxidant constituents such as caffeine, caffeic acid, chlorogenic acid, and trigonelline have been studied for their protective effects against dementia and AD [18]-[20]. However, none of these compounds had any effects on the phosphorylation of TrkB, even at a concentration of $100 \mu \mathrm{M}$ (Figure 2(C)).

\subsection{Effects of Coffee on the Cell Surface TrkB Expression}

Total cellular expression of TrkB proteins did not change during a 2-hour-long coffee treatment judged by the result of Figure 2(A). To determine if coffee reduced the TrkB expression on the cell surface, we measured the amount of TrkB on the cell surface with flow cytometry. As shown in Figure 3, the amounts of TrkB on the cell surface before and after treatment with coffee were similar.

\subsection{Effects of Coffee on BDNF Gene Expression in SH-SY5Y Cells}

BDNF induces its own gene expression through the BDNF/TrkB signaling pathway [2]. Accordingly, the addition of BDNF (20 ng/ml) increased the mRNA expression of BDNF by 2.2 -fold in the SH-SY5Y cells (Figure 4(A)). LY294002, a PI3K inhibitor, abolished this enhancement, which confirmed the involvement of TrkB signaling in this phenomenon (Figure 4(B)). Coffee ameliorated the increase of BDNF gene expression in a dosedependent manner. At a coffee concentration of $1 \%(\mathrm{v} / \mathrm{v})$, the expression level of BDNF almost reached to the basal level. 


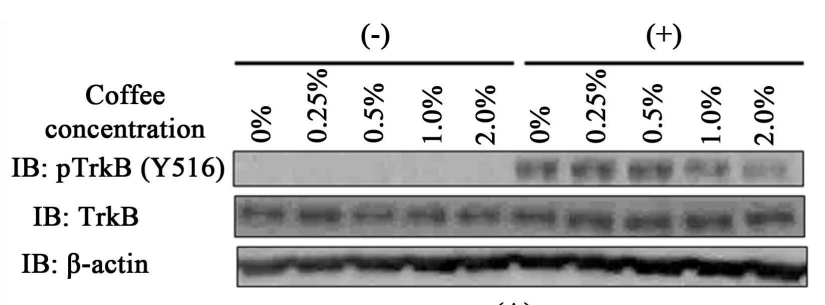

(A)

$(-)$

$(+)$

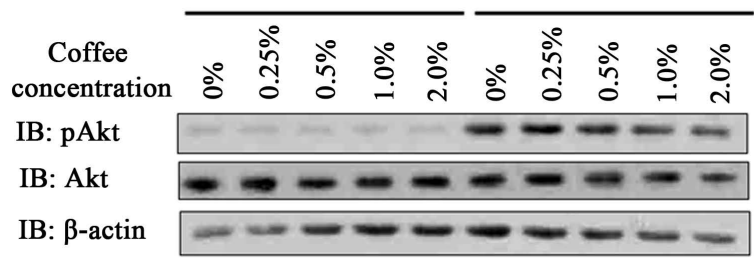

(B)

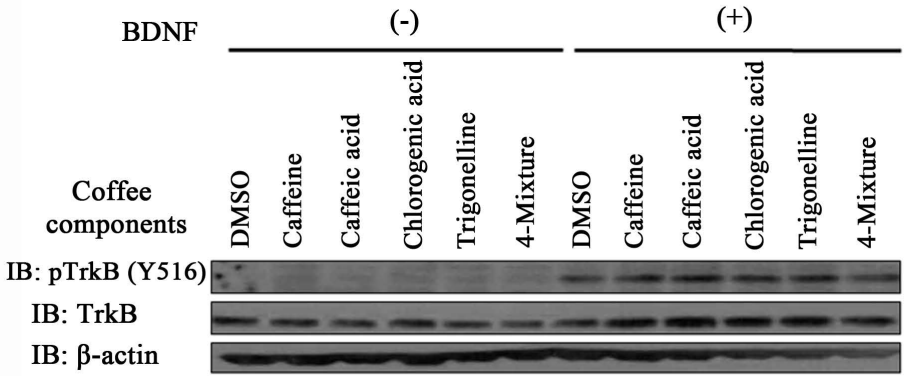

(C)

\begin{abstract}
Figure 2. Effects of coffee and of its major constituents on TrkB phosphorylation induced by BDNF. (A) SH-SY5Y cells were treated with coffee $(0 \%-2.0 \%)$ for 2 hours, and the cells were then treated with $20 \mathrm{ng} / \mathrm{ml}$ brain-derived neurotrophic factor (BDNF) for $15 \mathrm{mi}$ nutes. Using whole cell lysates ( $50 \mu \mathrm{g}$ proteins), the protein expression of tropomyosin receptor kinase B (TrkB) and phosphorylated TrkB at Y516 were analyzed with immunoblotting; (B) Effect of major coffee constituents on BDNF-mediated TrkB phosphorylation were analyzed as described in (A). Each compound was used at a concentration of $100 \mu \mathrm{M}$; (C) SH-SY5Y cells were treated with coffee $(0 \%-2.0 \%)$ and $20 \mathrm{ng} / \mathrm{ml} \mathrm{BDNF}$ as described in (A). Phosphorylation of Akt was analyzed in whole cell lysates (5 $\mu$ g proteins) using immunoblotting.
\end{abstract}

\title{
3.4. Effect of Coffee on the BDNF-Mediated Neurite Outgrowth
}

The BDNF/TrkB signaling pathway is involved in the regulation of neuronal morphology, as BDNF induces the branching and extension of axons and dendrites during development both in vitro and in vivo [21]. To determine whether coffee affects the cell morphology modulated by BDNF, we investigated the effects of coffee on neurite outgrowth in BDNF-treated SH-SY5Y cells. Cells were differentiated with $10 \mu \mathrm{M}$ ATRA for 4 days, and then were incubated with $50 \mathrm{ng} / \mathrm{ml}$ BDNF and/or coffee $(0 \%-2.0 \%)$ for additional 2 days. Changes in neurite outgrowth were determined by measuring the neurite length with microscopic analyses. Exogenous BDNF (50 $\mathrm{ng} / \mathrm{ml}$ ) increased the length of neurites to $145 \%$ of the control, whereas coffee $(>0.5 \%)$ significantly reduced the BDNF-mediated neurite outgrowth (115\% of the control at 2.0\% coffee) (Figure 5(B)).

\section{Discussion}

We found that coffee modulates BDNF/TrkB signaling by inhibiting TrkB autophosphorylation in differentiated SH-SY5Y cells. Inhibition of TrkB activation downregulated the BDNF-induced Akt activation and suppressed the BDNF-induced BDNF gene expression and neurite outgrowth. Several possible mechanisms might explain these results: 1) coffee might reduce the expression of TrkB at the cell surface; 2) coffee might inhibit BDNF binding to TrkB homodimers at the cell surface; 3) coffee might inhibit the autophosphorylation of TrkB in the 

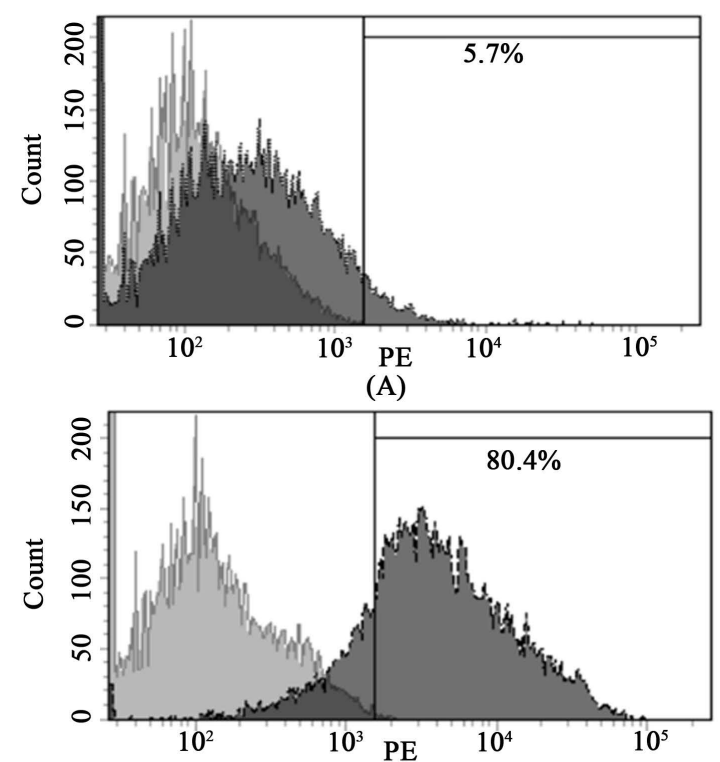

(B)

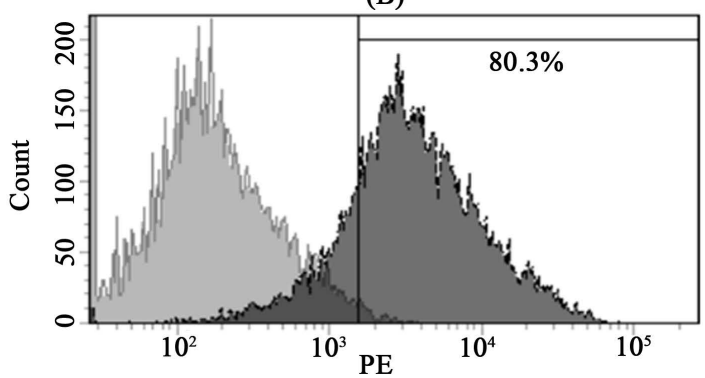

(C)

Figure 3. Effects of coffee on the amount of TrkB on the cell surface of SH-SY5Y cells. Differentiated cells were incubated in the anti-tropomyosin receptor kinase B (TrkB) antibody conjugated with phycoerythrin (PE) for 15 minutes on ice. The washed cells were analyzed with flow cytometry; $1 \times 10^{4}$ cells were analyzed for each experiment. Subpanels: (A) Undifferentiated cells; (B) and (C) Differentiated cells. Light gray, isotype control antibody; dark gray, anti-TrkB antibody. Vertical lines indicate the position of the maximal PE value of the isotype control in (A). Inserted numbers show the percentage of cells with a higher PE value than the value at the vertical line.

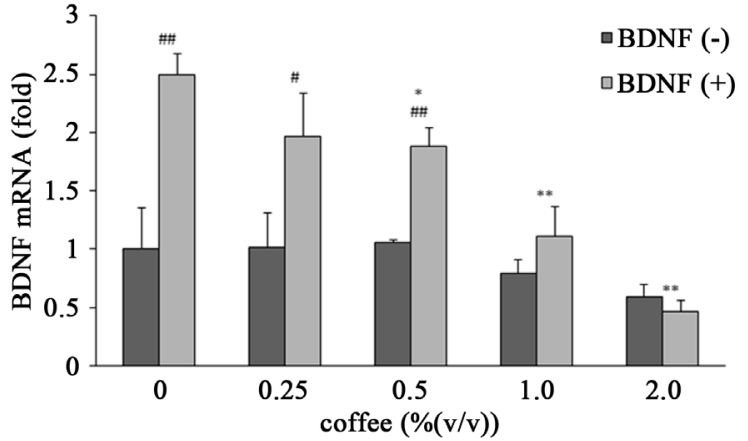

(A)

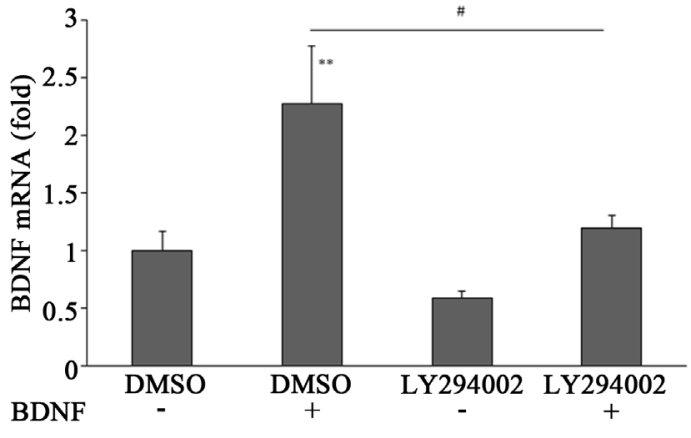

(B)

Figure 4. Effects of coffee on BDNF gene expression induced by BDNF. (A) Differentiated cells were treated with coffee (0\% $2.0 \%$ ) for 2 hours and then were incubated in $20 \mathrm{ng} / \mathrm{ml}$ BDNF for 4 hours. Total RNA was isolated from the treated cells, and the mRNA level of BDNF was analyzed with quantitative real-time PCR. Ctrl. $=$ control. ${ }^{*} p<0.05,{ }^{* * *} p<0.01$ vs. BDNF-treated cells $[\mathrm{BDNF}(+)] ;{ }^{\#} p<0.05,{ }^{\# \#} p<0.01$ vs. BDNF-untreated cells [BDNF(-)] $(\mathrm{n}=3)$; (B) Cells were treated with $20 \mathrm{ng} / \mathrm{ml} \mathrm{BDNF}$ and/or $10 \mu \mathrm{M} \mathrm{LY} 294002$ for $4 \mathrm{~h}$. BDNF mRNA level was analyzed as in (A). Dimethyl sulfoxide (DMSO) was the solvent for LY294002 (0.01\%). ${ }^{* *} p<0.01$ vs. BDNF(+); ${ }^{*} p<0.05$ vs. cells treated with LY294002 $(\mathrm{n}=3)$. 


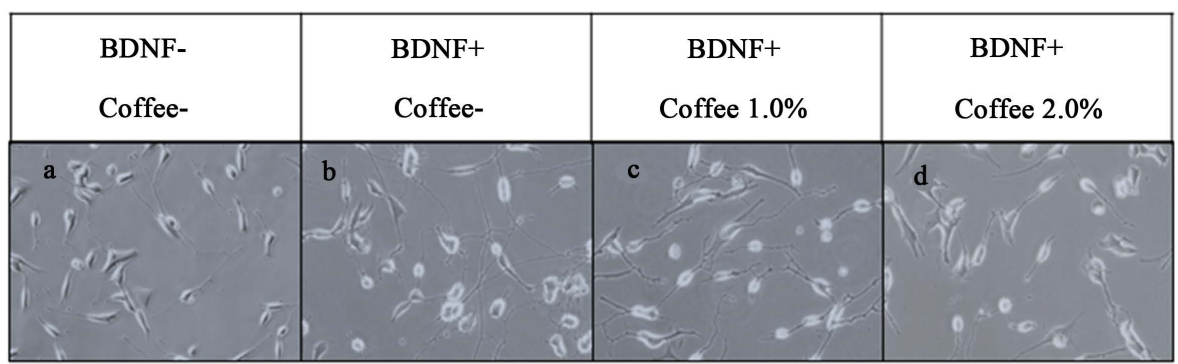

(A)

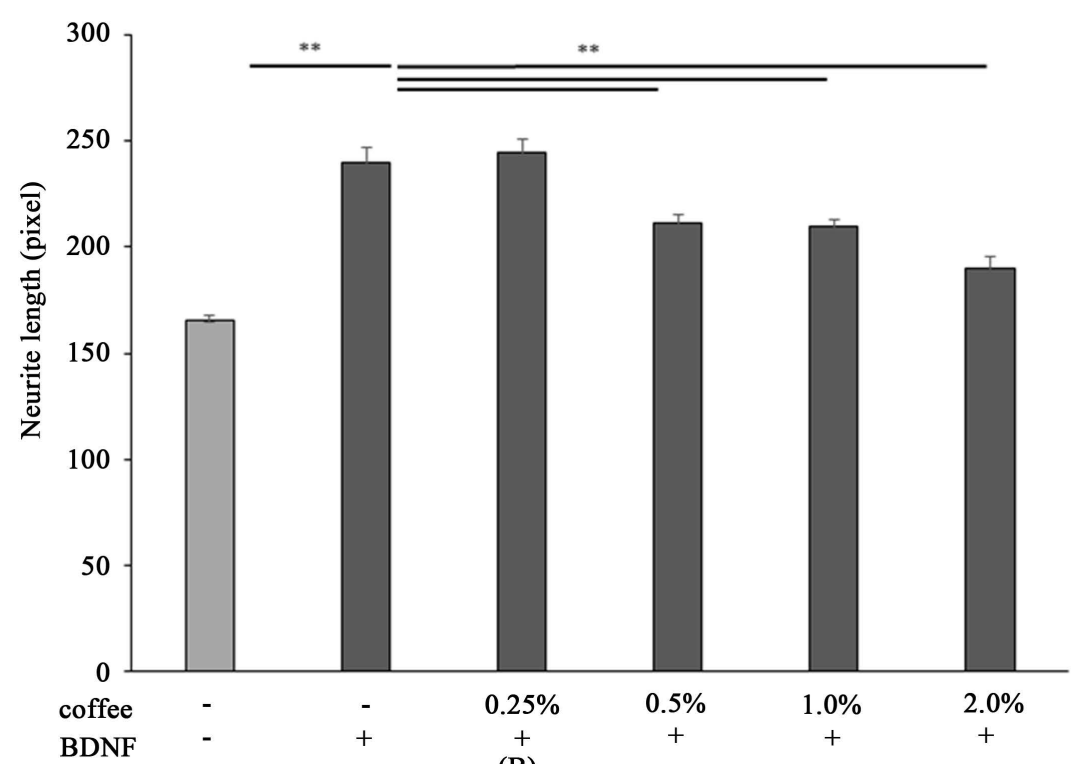

(B)

Figure 5. Effects of coffee on the BDNF-induced neurite outgrowth of SH-SY5Y cells. SH-SY5Y cells were differentiated with $10 \mu \mathrm{M}$ all-trans retinoic acid (ATRA) for 4 days and then incubated with $50 \mathrm{ng} / \mathrm{ml}$ brain-derived neurotrophic factor (BDNF) and coffee (0\% - 2.0\%) for 2 days. At least 4 fields per well were captured for analysis, and neurite length was measured with the Image $\mathrm{J}$ image software. The length is shown in pixels. ${ }^{* *} p<0.01(\mathrm{n}=120)$.

cell. As we found no significant change in the number of TrkB proteins at the surface of coffee-treated cells (Figure 3(B)), the second and third possibilities had to be investigated.

Even though it is not known yet whether the active components of coffee interact with TrkB directly or indirectly, several studies show that major components in coffee can modulate phosphorylation. Caffeic acid inhibits ERK phosphorylation in endothelial cells [22], and chlorogenic acid activates the AMP-activated protein kinase in skeletal muscle cells [23]. Alternatively, the activation of phosphatases, which may regulate TrkB autophosphorylation negatively [24], is another possible mechanism for the coffee-induced reduction of TrkB phosphorylation. Surprisingly, the major constituents of coffee (caffeine, caffeic acid, chlorogenic acid, and trigonelline) did not have any significant effect on BDNF/TrkB signaling in SH-SY5Y cells, although recent studies proposed that caffeine, chlorogenic acid, and trigonelline might be neuroprotective [12] [25] [26]. Further studies to identify the active compounds in coffee are warranted to clarify the inhibitory mechanism of coffee on TrkB phosphorylation in the cells.

We found that coffee reduced the BDNF-mediated induction of BDNF gene expression. Expression of BDNF is partially regulated by the cAMP response element (CRE) and CRE binding protein (CREB) [27]-[29]. Activated Akt phosphorylates CREB at Ser133, resulting in the upregulation of CREB target genes such as BDNF and B-cell lymphoma 2 (Bcl-2) [29]. Coffee-induced reduction of Akt phosphorylation may be responsible for the reduction of BDNF gene expression. Neurite outgrowth is one of the downstream effects of the Akt/CREB signaling cascade [30]. In this study, we showed that coffee significantly reduced the BDNF-induced neurite 
outgrowth. This morphological change may reflect the inhibitory effect of coffee on Akt-mediated BDNF signaling. Here we only analyzed the neurite lengths, but we could observe the coffee-mediated reduction of neurite branching, which might impair the successful integration of neurons. Molecular basis of these morphological changes should be investigated in the future.

Analytical studies detected hundreds of compounds in brewed coffee [31] [32]. Currently, it is not clear which active component(s) is responsible for the effects of coffee. Furthermore, it is not certain whether the active component(s) is absorbed and transferred to the brain, although studies show that the major components of coffee are rapidly absorbed in the stomach and small intestine and are distributed to several tissues including the brain [33]. Further studies including animal models are necessary to clarify the effect of the active compound on the human central nervous system.

Our present data indicate that daily coffee consumption may reduce the BDNF signaling if the active components of coffee reach to the brain. Therefore, our results are contradictory to the epidemiological concept that suggests the preventive effects of coffee in neurological disorders [11] [12]. Coffee may have other activities that contribute to prevent neurological disorders. Further studies are warranted to clarify this question.

\section{Acknowledgements}

We are grateful to Dr. K. Oka for his encouragement. This work was supported partially by a Grant-in-Aid from the Ministry of Education, Culture, Sports, Science, and Technology (MEXT) of Japan, and by a grant from the MEXT-Supported Program for the Strategic Research Foundation at Private Universities.

\section{Conflict of Interest}

The authors declare no conflicts of interest with respect to the authorship or publication of this article.

\section{References}

[1] Ohira, K. and Hayashi, M. (2009) A New Aspect of the TrkB Signaling Pathway in Neural Plasticity. Current Neuropharmacology, 7, 276-285. http://dx.doi.org/10.2174/157015909790031210

[2] Middlemas, D.S., Kihl, B.K., Zhou, J. and Zhu, X. (1999) Brain-Derived Neurotrophic Factor Promotes Survival and Chemoprotection of Human Neuroblastoma Cells. Journal of Biological Chemistry, 274, 16451-16460. http://dx.doi.org/10.1074/jbc.274.23.16451

[3] Bramham, C.R. and Messaoudi, E. (2005) BDNF Function in Adult Synaptic Plasticity: The Synaptic Consolidation Hypothesis. Progress in Neurobiology, 76, 99-125. http://dx.doi.org/10.1016/j.pneurobio.2005.06.003

[4] Bekinschtein, P., Cammarota, M., Igaz, L.M., Bevilaqua, L.R., Izquierdo, I. and Medina, J.H. (2007) Persistence of Long-Term Memory Storage Requires a Late Protein Synthesis- and BDNF-Dependent Phase in the Hippocampus. Neuron, 53, 261-277. http://dx.doi.org/10.1016/j.neuron.2006.11.025

[5] Heldt, S.A., Stanek, L., Chhatwal, J.P. and Ressler, K.J. (2007) Hippocampus-Specific Deletion of BDNF in Adult Mice Impairs Spatial Memory and Extinction of Aversive Memories. Molecular Psychiatry, 12, 656-670. http://dx.doi.org/10.1038/sj.mp.4001957

[6] Brunoni, A.R., Lopes, M. and Fregni, F. (2008) A Systematic Review and Meta-Analysis of Clinical Studies on Major Depression and BDNF Levels: Implications for the Role of Neuroplasticity in Depression. International Journal of Neuropsychopharmacology, 11, 1169-1180. http://dx.doi.org/10.1017/S1461145708009309

[7] Dwivedi, Y. (2009) Brain-Derived Neurotrophic Factor: Role in Depression and Suicide. Neuropsychiatric Disease and Treatment, 5, 433-449. http://dx.doi.org/10.2147/NDT.S5700

[8] Arancio, O. and Chao, M.V. (2007) Neurotrophins, Synaptic Plasticity and Dementia. Current Opinion in Neurobiology, 17, 325-330. http://dx.doi.org/10.1016/j.conb.2007.03.013

[9] Zuccato, C. and Cattaneo, E. (2009) Brain-Derived Neurotrophic Factor in Neurodegenerative Diseases. Nature Reviews Neurology, 5, 311-322. http://dx.doi.org/10.1038/nrneurol.2009.54

[10] Fumagalli, F., Racagni, G. and Riva, M.A. (2006) Shedding Light into the Role of BDNF in the Pharmacotherapy of Parkinson's Disease. The Pharmacogenomics Journal, 6, 95-104. http://dx.doi.org/10.1038/sj.tpj.6500360

[11] Eskelinen, M.H., Ngandu, T., Tuomilehto, J., Soininen, H. and Kivipelto, M. (2009) Midlife Coffee and Tea Drinking and the Risk of Late-Life Dementia: A Population-Based CAIDE Study. Journal of Alzheimer's Disease, 16, 85-91.

[12] Santos, C., Costa, J., Santos, J., Vaz-Carneiro, A. and Lunet, N. (2010) Caffeine Intake and Dementia: Systematic Review and Meta-Analysis. Journal of Alzheimer's Disease, 20, S187-S204. 
[13] Connolly, S. and Kingsbury, T.J. (2010) Caffeine Modulates CREB-Dependent Gene Expression in Developing Cortical Neurons. Biochemical and Biophysical Research Communications, 397, 152-156. http://dx.doi.org/10.1016/j.bbrc.2010.05.054

[14] Costa, M.S., Botton, P.H., Mioranzza, S., Ardais, A.P., Moreira, J.D., Souza, D.O. and Porciúncula, L.O. (2008) Caffeine Improves Adult Mice Performance in the Object Recognition Task and Increases BDNF and TrkB Independent on Phospho-CREB Immunocontent in the Hippocampus. Neurochemistry International, 53, 89-94. http://dx.doi.org/10.1016/j.neuint.2008.06.006

[15] Alhaider, I.A., Aleisa, A.M., Tran, T.T. and Alkadhi, K.A. (2011) Sleep Deprivation Prevents Stimulation-Induced Increases of Levels of P-CREB and BDNF: Protection by Caffeine. Molecular and Cellular Neuroscience, 6, 742-751. http://dx.doi.org/10.1016/j.mcn.2011.02.006

[16] Reyes-Izquierdo, T., Nemzer, B., Shu, C., Huynh, L., Argumedo, R., Keller, R. and Pietrzkowski, Z. (2013) Modu Latory Effect of Coffee Fruit Extract on Plasma Levels of Brain-Derived Neurotrophic Factor in Healthy Subjects. British Journal of Nutrition, 110, 420-425. http://dx.doi.org/10.1017/S0007114512005338

[17] Kaplan, D.R., Matsumoto, K., Lucarelli, E. and Thiele, C.J. (1993) Induction of TrkB by Retinoic Acid Mediates Biologic Responsiveness to BDNF and Differentiation of Human Neuroblastoma Cells. Eukaryotic Signal Transduction Group. Neuron, 11, 321-331. http://dx.doi.org/10.1016/0896-6273(93)90187-V

[18] Arendash, G.W. and Cao, C. (2010) Caffeine and Coffee as Therapeutics against Alzheimer's Disease. Journal of Alzheimer's Disease, 20, S117-S126.

[19] Oboh, G., Agunloye, O.M., Akinyemi, A.J., Ademiluyi, A.O. and Adefegha, S.A. (2013) Comparative Study on the Inhibitory Effect of Caffeic and Chlorogenic Acids on Key Enzymes Linked to Alzheimer's Disease and Some Pro-Oxidant Induced Oxidative Stress in Rats’ Brain—In Vitro. Neurochemical Research, 38, 413-419. http://dx.doi.org/10.1007/s11064-012-0935-6

[20] Makowska, J., Szczesny, D., Lichucka, A., Giełdoń, A., Chmurzyński, L. and Kaliszan, R. (2014) Preliminary Studies on Trigonelline as Potential Anti-Alzheimer Disease Agent: Determination by Hydrophilic Interaction Liquid Chromatography and Modeling of Interactions with Beta-Amyloid. Journal of Chromatography B-Analytical Technologies in the Biomedical and Life Sciences, 968, 101-104. http://dx.doi.org/10.1016/j.jchromb.2013.12.001

[21] Shih, C.H., Chen, C.J. and Chen, L. (2013) New Function of the Adaptor Protein SH2B1 in Brain-Derived Neurotrophic Factor-Induced Neurite Outgrowth. PLOS ONE, 8, e79619. http://dx.doi.org/10.1371/journal.pone.0079619

[22] Kim, S.R., Jung, Y.R., Kim, D.H., An, H.J., Kim, M.K., Kim, N.D. and Chung, H.Y. (2014) Caffeic Acid Regulates LPS-Induced NF- $\kappa$ B Activation through NIK/IKK and c-Src/ERK Signaling Pathways in Endothelial Cells. Archives of Pharmacal Research, 37, 539-547. http://dx.doi.org/10.1007/s12272-013-0211-6

[23] Ong, K.W., Hsu, A. and Tan, B.K. (2013) Anti-Diabetic and Anti-Lipidemic Effects of Chlorogenic Acid Are Mediated by Ampk Activation. Biochemical Pharmacology, 85, 1341-1351. http://dx.doi.org/10.1016/j.bcp.2013.02.008

[24] Ozek, C., Kanoski, S.E., Zhang, Z.Y., Grill, H.J. and Bence, K.K. (2014) Protein-Tyrosine Phosphatase 1B (PTP1B) Is a Novel Regulator of Central Brain-Derived Neurotrophic Factor and Tropomyosin Receptor Kinase B (TrkB) Signaling. The Journal of Biological Chemistry, 289, 31682-31692. http://dx.doi.org/10.1074/jbc.M114.603621

[25] Okada, Y. and Okada, M. (2013) Protective Effects of Plant Seed Extracts against Amyloid $\beta$-Induced Neurotoxicity in Cultured Hippocampal Neurons. Journal of Pharmacy \& Bioallied Sciences, 5, 141-147. http://dx.doi.org/10.4103/0975-7406.111819

[26] Kim, J., Lee, S., Shim, J., Kim, H.W., Kim, J., Jang, Y.J., Yang, H., Park, J., Choi, S.H., Yoon, J.H., Lee, K.W. and Lee, H.J. (2012) Caffeinated Coffee, Decaffeinated Coffee, and the Phenolic Phytochemical Chlorogenic Acid UpRegulate NQO1 Expression and Prevent $\mathrm{H}_{2} \mathrm{O}_{2}$-Induced Apoptosis in Primary Cortical Neurons. Neurochemistry International, 60, 466-474. http://dx.doi.org/10.1016/j.neuint.2012.02.004

[27] Aid, T., Kazantseva, A., Piirsoo, M., Palm, K. and Timmusk, T. (2007) Mouse and Rat BDNF Gene Structure and Expression Revisited. Journal of Neuroscience Research, 85, 525-535. http://dx.doi.org/10.1002/jnr.21139

[28] Zou, J. and Crews, F. (2006) CREB and NF- $\kappa$ B Transcription Factors Regulate Sensitivity to Excitotoxic and Oxidative Stress Induced Neuronal Cell Death. Cellular and Molecular Neurobiology, 26, 385-405. http://dx.doi.org/10.1007/s10571-006-9045-9

[29] Zhang, L., Zhao, H., Zhang, X., Chen, L., Zhao, X., Bai, X. and Zhang, J. (2013) Nobiletin Protects against Cerebral Ischemia via Activating the p-Akt, p-CREB, BDNF and Bcl-2 Pathway and Ameliorating BBB Permeability in Rat. Brain Research Bulletin, 96, 45-53. http://dx.doi.org/10.1016/j.brainresbull.2013.04.009

[30] Read, D.E. and Gorman, A.M. (2009) Involvement of Akt in Neurite Outgrowth. Cellular and Molecular Life Sciences, 66, 2975-2984. http://dx.doi.org/10.1007/s00018-009-0057-8

[31] Chang, K.L. and Ho, P.C. (2014) Gas Chromatography Time-of-Flight Mass Spectrometry (GC-TOF-MS)-Based Metabolomics for Comparison of Caffeinated and Decaffeinated Coffee and Its Implications for Alzheimer's Disease. 
PLoS ONE, 9, e104621. http://dx.doi.org/10.1371/journal.pone.0104621

[32] Somoza, V., Lindenmeier, M., Wenzel, E., Frank, O., Erbersdobler, H.F. and Hofmann, T. (2003) Activity-Guided Identification of a Chemopreventive Compound in Coffee Beverage Using in Vitro and in Vivo Techniques. Journal of Agricultural and Food Chemistry, 51, 6861-6869. http://dx.doi.org/10.1021/jf034750e

[33] Higdon, J.V. and Frei, B. (2006) Coffee and Health: A Review of Recent Human Research. Critical Reviews in Food Science and Nutrition, 46, 101-123. http://dx.doi.org/10.1080/10408390500400009 